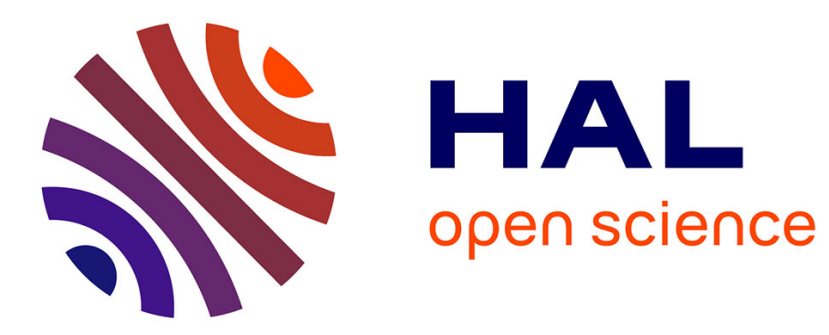

\title{
Product Data Management - Defining the Used Terms
}

\author{
Merja Huhtala, Mika Lohtander, Juha Varis
}

\section{To cite this version:}

Merja Huhtala, Mika Lohtander, Juha Varis. Product Data Management - Defining the Used Terms. 11th IFIP International Conference on Product Lifecycle Management (PLM), Jul 2014, Yokohama, Japan. pp.387-396, 10.1007/978-3-662-45937-9_38 . hal-01386542

\section{HAL Id: hal-01386542 \\ https://hal.inria.fr/hal-01386542}

Submitted on 24 Oct 2016

HAL is a multi-disciplinary open access archive for the deposit and dissemination of scientific research documents, whether they are published or not. The documents may come from teaching and research institutions in France or abroad, or from public or private research centers.
L'archive ouverte pluridisciplinaire HAL, est destinée au dépôt et à la diffusion de documents scientifiques de niveau recherche, publiés ou non, émanant des établissements d'enseignement et de recherche français ou étrangers, des laboratoires publics ou privés. 


\title{
Product Data Management - Defining the Used Terms
}

\author{
Merja Huhtala ${ }^{1}$, Mika Lohtander ${ }^{1}$, and Juha Varis ${ }^{1}$ \\ Lappeenranta University of Technology, LUT School of Technology, LUT Mechanical \\ Engineering, Lappeenranta, Finland \\ \{merja.huhtala, mika.lohtander, juha.varis\}@lut.fi
}

\begin{abstract}
The Product Data Management (PDM) system and its associated terminology have changed over the years. Product Lifecycle Management (PLM) has become the predominant system and tends to overshadow PDM. However, PDM remains relevant and is a system commonly used by design engineers; mainly as a storage place for drawings and a place where drawings can be found for further editing.

To obtain full benefit from the PDM/PLM systems, precise definitions are required. Without such definitions, the systems cannot function as they should and they cannot be used optimally. Furthermore, shortcomings in definitions may lead to a situation where the engineering community is unaware of the kind of help the systems can offer.

The main focus of this conference paper is definition of some of the terms inherent to PDM/PLM systems and their data.
\end{abstract}

Keywords: Product Data Management, PDM, data, product data

\section{Introduction}

Industrial production has increased over the years, especially in China. Competition on global markets is intense and this has led to a situation where companies try to reduce design and manufacturing costs by moving such activities to low-cost countries. Figure 1 presents data for a number of different countries and shows how their industrial production has increased over the last decade. When looking at the situation from Finland's point of view, it can be seen that production, as elsewhere in the Euro area, has not increased greatly. The trend in Finland seems to be to that production and design are being moved to low-cost countries; especially to China, Korea and India. [1] 


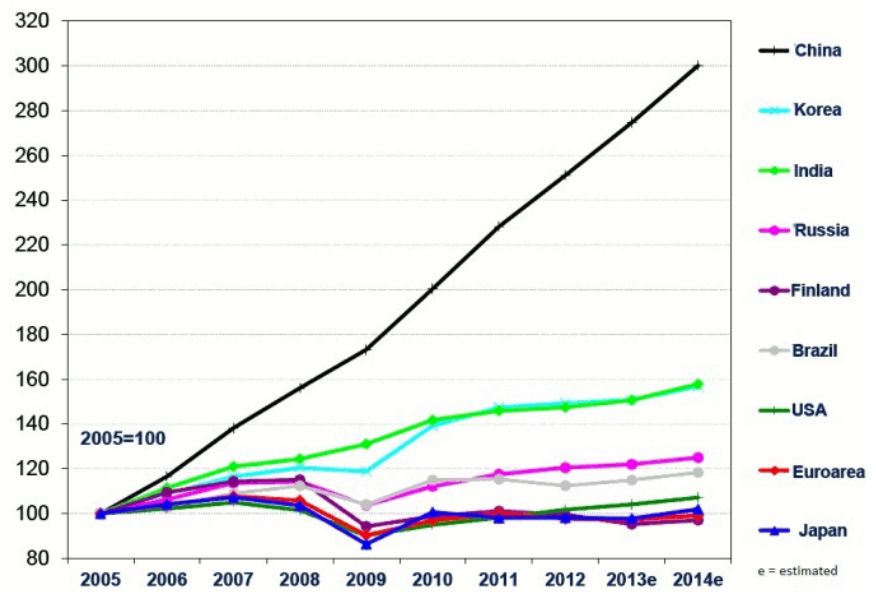

Fig. 1. Industrial production development in different countries [2]

Increasingly competitive markets are putting pressure on engineering work: designs have to be completed in relatively short time periods. Robinson [3] recently researched time usage in the work of design engineers. He compared the latest results with earlier findings and made a surprising observation: time usage of design engineers remains the same as 20 years earlier. Technical tools have developed and new tools have become available to facilitate the work of design engineers, but nevertheless most of design engineers' time is taken up with something other than technical work. Figure 2 presents how design engineers' time is allocated. [3]

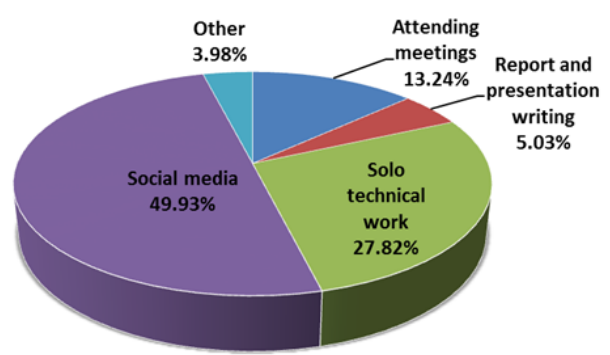

Fig. 2. Engineers' time consumptions [3]

The nature of modern markets and increased emphasis on product development means that companies can ill afford ineffective design practices, and effective data management is critically important. Product Data Management (PDM) is a system 
that can help companies remain competitive in rapidly changing markets and that can make engineers use time more effectively.

\section{Method}

This conference paper was written as part of the Finnish Metals and Engineering Competence Cluster (FIMECC)'s MANU P3 Product Knowledge Management in Global Networks (ProMaGNet) -project. During the ProMaGNet project interviews were done in different Finnish industrial companies. It was clearly noticed that the definition of PDM was different in every company: generally, PDM was handled either as separately PDM or as an element of Product Lifecycle Management (PLM). Often, PDM was seen only as a design engineering tool whereas PLM was seen as a lifecycle tool for the company as a whole. Without a clear definition of the terms, use of these two systems cannot be effective.

This paper is based on study of how to determine terms associated with PDM. The definitions are based on literature review and relevant standards. Three main standards [4-6] were found and used alongside information published in journal articles and books.

\section{$3 \quad$ Introduction to PDM system}

The Product Data Management system was created in the 1980s. Its main purpose was to help design engineers save time and get products faster to the production stage. In the first stages of PDM, it only served design engineers by being a storage place for drawings: drawings were easy to find and subsequent changes to drawings easier to handle. These features helped reduce engineering costs. In the 1990s most data became electronic and the PDM system spurred companies to realize the importance of data handling. [7-8] Concerns about product development and time usage of design engineers (Fig. 1 and Fig 2.) led to pressure to use the PDM system more effectively. However, the use of this system did not affect the time spent on technical work as much as it should have.

Documentation in industrial design should start from the very beginning of the design process. The Aberdeen Group [9] examined the point where companies' documentation is started. In most cases, documentation started when a product concept was initiated (60\%) and when a conceptual product structure was developed (22\%). However, some companies started the documentation after the BOM (Bill of Materials) was developed or finalized. It can be seen that companies have understood the significance of documentation; without documentation drawings may go missing, which may cause the design process to take more time. Mainly because designs are not final in the first draft, iterative changes to the drawings have to be possible. [9] In such iterative processes, the flexibility of the systems and subsystems is crucial for improved production and design. By utilizing the 
PDM system companies can make sure that designs are available to those who may need them; this is a stage of documentation flexibility. Workflow and product data can be managed more effectively. [10]

The amount of used product data in companies has grown in recent years; consequently, storage capacity has also increased. For example, in 2000 global disk storage per person (GDSP) was $472 \mathrm{MB}$ and in 2008 it was over $400 \%$ greater, 2000 MB. [11] Production patterns have also changed: it is now common that products have many different variants. To handle these variants and associated changes to designs, it is crucial that data handling is fast. It is also important that the information is available for many years: many products are long-lasting and products may need spare parts and maintenance long after the original design was made. [10]

In light of developments in industrial production, design engineers' time usage, documentation starting point and disk storage, it is important that the PDM system works as it should. PDM has certain key functions, which are shown in Figure 3. If the system works as it should, the benefits accruing from the system are, according to [10] and [12-15]: the data can be better controlled; people have easy access to data; the latest versions of drawings are always available and change management thus easier to handle; all data are stored in one safe place; and the information is available in an easily accessible format (e. g. PDF) to whomever may need it.

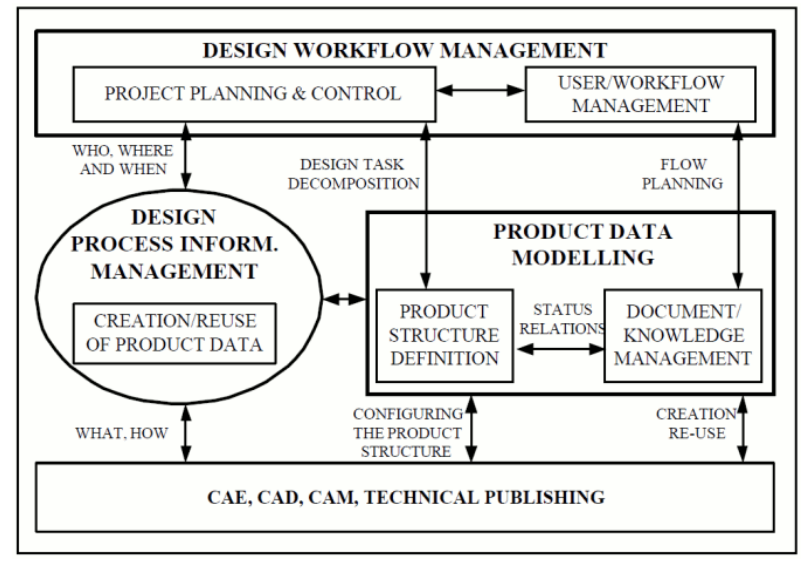

Fig. 3. Key functions of PDM [15]

All people in the company have to be aware of the PDM system, from those involved in manufacturing to top managers. For this reason, the PDM system has to be a part of the business strategy of the company. PDM may be an individual system but it has to be integrated with other systems, e.g. design software and software used on the manufacturing plant floor and in purchasing operations. PDM 
has to be able to link all the systems together [10] but before the actual integration and the purchase of a system it has to be clear what kind of system is going to be purchased and what are the definitions of the system and its related terms.

\section{Definitions of used terms}

In the authors' opinion the most important terms in the context of this discussion are: data, product data and product data management. Firstly, to make sure that the PDM system works as it should it has to be clear what PDM actually is and what it stands for. Secondly, if the terms data and product data are unclear, it may mean that information entered into the system is not valid. Clearly, without valid information it may not be possible to manufacture the part or product.

\subsection{Data - the definition}

According to SFS-ISO standard 16792 [6] the definition for data is "information represented in a formal manner suitable for communication, interpretation or processing by human beings or computers". The terms data and document are normally used as synonyms. The definition for document, according to SFS-EN ISO standard 11442:en [5], is a "fixed and structured amount of information that can be managed and interchanged as a unit between users and systems”.

Other sources define the term data differently and the definition of data can be different at different stages of the product, i.e. during different parts of its lifecycle. The prime function of data is to define the product: defined properties can be physical and/or functional properties. The data has informational value through its images and descriptions of its characteristics. The data can be lifecycle data: data between the starting point (of designing) and the end point (when the product is recycled). And the data can be handled as meta data, i.e. information about who has produced the data and where the data is located. [16]

Companies need information to enable operations, and companies' products include information that enables them to be manufactured. This information is data and includes, for example, information about the materials used and functionality of a product. Product data also include information about suppliers and vendors and should include information that has value for customers. Thus, the data comprise different types of information and this information together can be called master data. [17] It should be borne in mind that not only the product is important for the company, the data is also important. According to [18] the data should be treated like a product. When treating data as a product, Stark [10] claims: "The definition of the product does not have to be identical at all stages, but it does have to be consistent."

Although some standards attempt to define the term, there is no widely accepted definition of data that is considered valid throughout all areas of engineering and definitions given by design engineers, people involved in purchasing and 
those in manufacturing all differ. Not only do the individuals give different definitions, different design programs also handle and understand the word differently. [10] This situation is described in Figure 4; the different units in a company see the definition of data differently, which means that also the product is seen differently [19].

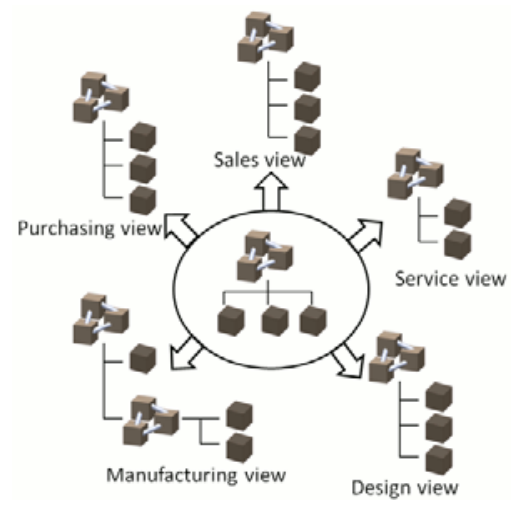

Fig. 4. Different points of view of the data (and the product) [19]

\subsection{Product Data - the definition}

When starting to define the term Product Data, the product should first be defined. It can be seen from Figure 4 that the product can be seen differently in different departments within a company. Generally, the terms part and product are taken as meaning the same thing. But according to [20], these two terms are different, although related. A part is an already manufactured object or soon going to be manufactured. While a product is an object which has been already sold, or is going to be sold soon. However, standard SFS-EN ISO 10303-210:en [4] gives the definition for a part as: "a product with operational functionality that is expected to be used as a component of one or more assembled products".

According to Rueckel et al. [21], a product description can include: CADmodels, simulation models, FEM structures, calculation results, CAD-drawings, object list, task schedules, NC-programs, test plans, assembly instructions, QAdocuments et cetera. By these different classifications the product can be fully described. It should be noticed that these are most common classifications and in every product all of these classifications may not exist. But the main key is that every product has to have some kind of information which describes the product so it can be identified and manufactured. [21]

The simplest definition for product data is given by Kropsu-Vehkapera [22]: product data is data that is related to the product. Product data can be divided to three different sectors: product description, lifecycle data and meta data. All these 
sectors are related to each other, e.g. lifecycle data does not exist if there is no description for the product. [22]

Standard SFS-EN ISO 10303-210:en [4] has its own definition for product data: "all data that is used to describe aspects of a product." But according to Stark [10]; "The term 'product data' includes all data related both to a product and to the processes that are used to design it, to produce it, to use it and to support it." This means that product data is not created only by designing engineers, all units that are somehow connected to the manufacturing and selling of the product create product data. [10]

Specifications depend on the product and therefore the product data depend on these specifications. The product includes not only the physical product itself but also the product specifications and product definition. These three aspects together create the product data. Process planning and materials are included in the data for the product definition, and data for the actual product describe the object physically (measurements) and from the point of view of the design process (e.g. the design date) [20] A product data model is needed to define the term product data. [23]

\subsection{Product Data Management (PDM) - the definition}

According to Burden [12]: "PDM is often defined differently by different industries and consequently it can be a rather difficult and elusive entity to grasp, implement, and measure.” The main purpose of PDM is to handle product-related data, and this has led to a situation where the system can be given different names, such as Engineering Document Management, Technical Information Management etc. However, the system essentially concentrates on managing the data. The PDM system can be seen as a supporting tool for PLM. On the other hand, the PDM can be seen as a part of PLM. The reason why these two terms have become confused is not clear; from the point of view of some researchers, over the years PDM has grown to be PLM. [24-26]

Figure 5 illustrates how the PDM system is linked to PLM. It can be seen that PDM supports the PLM concept and without PDM the PLM system cannot work properly. [15] According to Könst et al. [11] the definition for PDM is "a business wide methodology and strategy which makes the appropriate product-related and process-related information accessible to the appropriate people at the appropriate stage in the product lifecycle." 


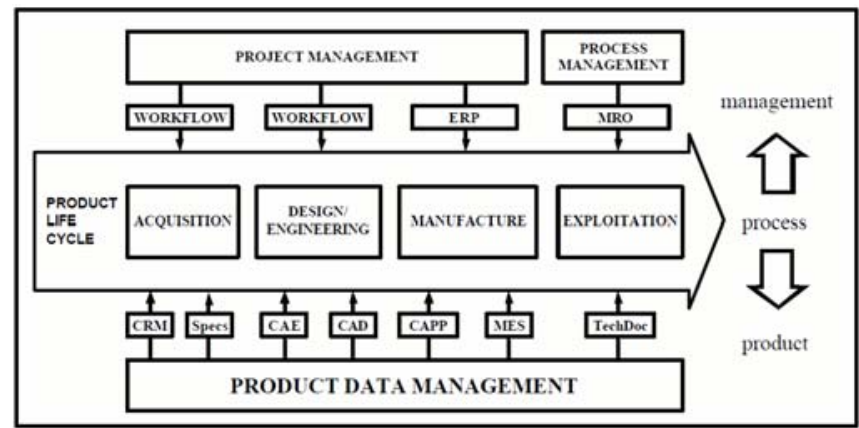

Fig. 5. Position of PDM system according to PLM [15]

The PDM system can also be seen as an individual system, as in Bergsjö et al. [27] and Chan and Yu [28]. Although the system is separate it still helps to organize co-operation between different units in the company. Although PDM is its own application, Stark [10] states that PDM is always part of PLM. PLM could not work without PDM and the main task of PDM is to manage information during the product lifecycle. At the same time, PDM improves productivity: workflow in the company can be fully controlled. [10]

As mentioned earlier, the data should be available to all who may need it. Integration between PDM systems and different CAD software makes this possible. Effective integration is the only way to fully control the information created. [21] Philpotts [29] points out that companies have many different kinds of management systems and claims that the PDM is a solution to integrate these systems together. All the information is in electronic format and safe in one place, and the data can be revised, used as a basis for new products, and viewed to get more information about the product. However, PDM is not just about handling data; PDM is a tool for communication and notification between system users. [29]

\section{Conclusions}

Based on the above discussion, the following conclusions can be drawn. Definitions for the terms vary greatly and depend on the source. Data can be handled as a product, but a common factor found in the literature is that it is important to handle data correctly within the company. Data is related to the product and products are parts that companies produce to get profit. Co-operation inside the company is crucial: the product should include data that is valid for each department such that they can all do their work on time and in an effective way. Data should thus not be from one point of view (e. g. from design engineers' point of view) alone: the main purpose of the data is to describe the product.

The system itself that handles the data is PDM. PDM, on the other hand, is the core of PLM. These two systems mainly occur together and which term should be 
used depends mainly on the lifecycle stage of the product. In the design stage engineers tend to use the PDM system, but after manufacturing of the product employees talk about PLM. However the main purpose of PDM/PLM is to store data and keep it available even for decades. The system should integrate all programs in the company, including those related with subcontractors.

The PDM/PLM system is used in many different ways and the system is different in every company. But to get full benefit from PDM/PLM, it is crucial that the terms are defined clearly: what is important and useful data for the company, what actually is product data, and last but not least, what is the PDM/PLM system and how should it be used.

\section{References}

1. The Federation of Finnish Technology Industries http://www.teknologiateollisuus.fi/ file/7250/jpkv07af_Teollisuustuotannonkehitysvuosittain.pdf.html

2. The Federation of Finnish Technology Industries www.teknologiateollisuus.fi/ file/2764/Metallien_hintoja.pdf.html.

3. Robinson, M. A.: How design engineers spend their time: Job content and task satisfaction. Design studies. 33, 391-425 (2012)

4. SFS-EN ISO 10303-210:en: Industrial automation systems and integration. Product data representation and exchange. Part 210: Application protocol: Electronic assembly, interconnection, and packaging design (ISO 10303-210:2001). European Committee for Standardization (CEN), Brussels (2003)

5. SFS-EN ISO 11442:en: Technical product documentation- Document management (ISO 11442:2006). European Committee for Standardization (CEN), Brussels (2006)

6. SFS-ISO 16792: Technical product documentation - digital product definition data practices. Finnish Standards Association (SFS), Helsinki (2010)

7. Ahmed, Z., Gerhard, D.: Contributions of PDM Systems in Organizational Technical Data Management. In: The first IEEE International Conference on Computer, Control \& Communication. IEEE Press, (2007)

8. Borrmann, A., Schorr, M., Obergriesser, M., Ji, J., Wu, I-C., Günthner, W., Euringer, T., Rank, E.: Using Product Data Management Systems for Civil Engineering Projects - Potentials and Obstacles. In: Caldas, C. H., O’Brien, W. J. (eds.) Proceedings of the 2009 ASCE International Workshop on Computing in Civil Engineering, EUROSPAN, London (2009)

9. The Aberdeen Group, http://www.plm.automation.siemens.com/zh_cn/Images/ Aberdeen_Enabling_Product_Innovation_The_Roles_of_ERP_and_PLM_in_the_ Product_Lifecycle_05-12-01_tcm78-4641.pdf

10. Stark, J.: Product Lifecycle Management - 21st Century Paradigm for Product Realisation. Springer-Verlag London Limited, USA (2005)

11. Könst, J. S., La Fontaine, J., Hoogeboom, M., Wilkinson, J.: Product Data Management - A Strategic Perspective. Maj Engineering Publishing, Netherland (2009)

12. Burden, R.: PDM : product data management : a guide to PLM: product lifecycle management. Resource Publishing, (2003)

13. Liu, D. T., Xu, X. W.: A review of web-based product data management systems. Computers in Industry 44, 251-262 (2001) 
14. Sendler, U., Wawer, V.: CAD and PDM: optimizing Processes by Integrating Them. Hanser Publications, München (2008)

15. Storga, M., Pavlic, D., Marjanovic, D.: Reducing design development cycle by data management within the design office. In: International conference on Engineering Design, ICED 01. (2001)

16. Saaksvuori, A., Immonen, A.: Product Lifecycle Management. Springer, Heidelberg (2005)

17. Loshin, D.: Master Data Management. Elsevier, United States (2009)

18. Wang, R. Y., Lee, Y. W., Pipino, L. L., Strong, D. M.: Manage Your Information as a Product. Sloan Management Review 39, 95-105 (1998)

19. Kemppainen, T., Kropsu-Vehkaperä, H., Haapasalo, H.: Introduction Product Data Ownership Network. University of Oulu: Research Reports in Department of Industrial Engineering and Management (2011)

20. McKay, A., Bloor, M. S., de Pennington A.: A Framework for Product Data. IEEE Transactions on Knowledge and Data Engineering 8, 825-838 (1996)

21. Rueckel, V., Koch, A., Feldmann, K., Meerkamm, H.: Process Data Management for the Shortening of the Whole Product Creation Process. In: Shen, W., Chao, K-M., Lin, Z., Barthès, J-P. A., James, A. (eds.) Computer Supported Cooperative Work in Design II, $9^{\text {th }}$ International Conference, CSCWD 2005, vol. 3865, pp. 616-625 (2006)

22. Kropsu-Vehkaperä, H.: Product structure and lifecycle management: A systematic literature review. In: Haapasalo, H., Kropsu-Vehkaperä, H. (eds.) The 3rd Nordic Innovation Research Conference - NIR 2008 - IEM Arctic Workshop. Oulu University press, Oulu (2009)

23. Lanz, M., Kallela, T., Järvenpää, E., Tuokko, R.: Ontologies as an Interface between Different Design Support Systems. In: Dimitrov, D. P., Mladenov, V., Jordanova, S., Mastorakis, N. (eds.) Proceedings of the 9th WSEAS International Conference on Neural Networks, pp. 202-207. Bulgaria, (2008)

24. Abramovici, M., Gerhard, D., Langenberg, L.: Application of PDM technology for Product Life Cycle Management. In: Krause, F-L., Selinger, G. (eds.) Life Cycle Networks: Proceedings of the 4th CIRP International Seminar on Life Cycle Springer, Engineering, pp. 17-31. Berlin (1997)

25. COE, http://www.coe.org/newsnet/feb04/industry.cfm

26. Cao, H., Folan, P.: Product life cycle: the evolution of a paradigm and literature review from 1950-2009. Production Planning \& Control 23, pp. 641-662 (2012)

27. Bergsjö, D., Malmqvist, J., Ström, M.: Architectures for mechatronic product data integration in PLM systems. In: Marjanovic, D. (ed.) International Design Conference Design, pp. 1065-1076. Croatia (2006)

28. Chan, E., Yu, K. M.: A concurrency control model for PDM. Computers in Industry 58, pp. 823-831 (2007)

29. Philpotts, M.: An introduction to the concepts, benefits and terminology of product data management. Industrial Management \& Data Systems 96, pp. 11- 17 (1996) 